\title{
The Efficiency and Productivity for Manufacturing Industries in China, with Network Structure Considering Undesirable Output
}

\author{
Jing $\mathrm{Li}^{1}$, Peng Zhou ${ }^{1}$ \& Yongli Zhu ${ }^{1}$ \\ ${ }^{1}$ School of Economics, Hefei University of Technology, Hefei, China \\ Correspondence: Peng Zhou, School of Economics, Hefei University of Technology, Hefei, China. Tel: \\ 86-137-3922-3658. E-mail: zhoupeng@mail.hfut.edu.cn
}

Received: April 10, 2014 Accepted: July 29, 2014 Online Published: August 15, 2014

doi:10.5539/ass.v10n18p63

URL: http://dx.doi.org/10.5539/ass.v10n18p63

\begin{abstract}
Traditional DEA models have never considered the dynamics of the productive process and undesirable output simultaneously. This paper discovers a new network DEA model considering undesirable output and evaluates the efficiency of the Chinese 28 different manufacturing industries. Meanwhile, Malmquist TFP index is also applied to analyze the productive process. The empirical results indicate that: (a) Efficiency figures evaluated by new network DEA model are more accurate. (b) Low efficiency of industrial pollution solutions should be responsible for overall efficiency. (c) The general China's industrial TFP gradually rises. However, it is just an alternative growth instead of a continuous one.
\end{abstract}

Keywords: network DEA models, dynamics, undesirable output, TFP

\section{Introduction}

Since the reform and opening up policy, China's industrial system has made numerous achievements. In 2012, China's GDP reaches $7.8 \%$, while industry contributed more than $50 \%$. But under the traditional industrial development pattern, energy shortage and environment pollution have become the two major obstacles for sustainable development. According to the estimation of the World Bank, losses resulted from environmental pollution occupied about 10\% of China's GDP, and exceeded 2 trillion RMB in 2011. China has also been one of the world's leading pollutant emitters. Among the main pollutants, Emission of SO2 reaches 22.18 million tons high, while COD reaches 24.04 million tons in 2011. Scholars have actively been paying close attention to such serious environmental issues. Fare (1989) proposes Data Envelopment Analysis (DEA) to measure environmental behavior, which creates a new method of research on this field. Lee (2002) regards undesirable output as input variable, applying the traditional DEA model to calculate the efficiency of pollution emission. Färe and Grosskopf (2004) put forward the environmental DEA method from the viewpoint of disposability of undesirable output. Yang (2011) and $\mathrm{Wu}$ (2012) define the pollution as undesirable output and propose the comprehensive DEA efficiency evaluation based on environment evaluation method. Scholars make great contributions to this field, but they do not take into account the efficiency of intermediate processes. Most of intermediate products have important influences on the whole productive process. If we completely ignore the intermediate products, the obtained production efficiency is inaccurate and incomplete, which may mislead policy making. This article describes how the network DEA model to evaluate the efficiency and TFP for manufacturing industries in China, considering undesirable output.

The paper is organized as follows: Section 2, the literature review is shown. In Section 3, the derivation process of network DEA model considering the undesirable output. Some information and data are illustrated in Section 4. Section 5 provides the results, and comes to the conclusion in final section.

\section{Literature Review}

Concerning decision making units (DMUs), the early DEA models only consider efficiency of the whole productive process. However, they rarely take into account the efficiency of each stage. The procedures of production have been described in detail previously. Productive process includes many sub-stages, during which some intermediate products emerge. These intermediate products are not only the outputs of the previous stage, but also the inputs of the subsequent stage. Accumulating evidences prove that sub-procedures play a critical role in evaluating efficiency of the whole production process. 
Most traditional DEA models treat their reference technologies as black boxes. Inputs are transformed in this box into outputs. With the development of the society, in order to make good application and better evaluate organizational performance, adding more structures to the model has become a popular trend. Shephard and Färe (1975) put new insights into the complex organization by considering dynamics in the production process. Färe and Grosskopf (1996) propose a sequence of network models, which can be used to address various refinements of the standard DEA models as well. They formally advocate "network DEA" and introduce three network DEA models in 2000. DEA researchers begin to take advantage of network DEA models to evaluate the efficiency. In order to accurately describe the internal structure of DMUs, they reveal the black boxes, and consider the major DMU as a multi-stage system composed of many subunits. They look into DMUs to find out sources of inefficiency as well.

Wang et al. (1997) presents the DEA model of two stages of sequence type transformation process, Lewis and Sexton (2004) propose a sequence DEA model. Bi (2007) advances a DEA-based method to evaluate the performance of a two-stage serial production system with consideration of its internal mechanism. Estimation results from network DEA models and a direct productivity model (without customer satisfaction) are compared and affirm that the technical efficiency is lower than the network model (Mickael \& Magnus, 1999). Yu and Erwin (2008) provide a multi-activity network DEA model that represents both production and consumption technologies in a unified framework. Kaoru and Miki (2010) demonstrate a dynamic DEA model involving network structure in each period within the framework of a slacks-based measuring approach.

However, there are still several limitations to the study with respect to efficiency evaluation. Previous scholarly papers indicate that: (1) most scholars ignore the influence of undesirable output on efficiency evaluation when applying network DEA model, which make the actual productivity growth inaccurate. (2) in contrast, when they consider undesirable output in evaluating efficiency, they ignore the dynamic effect of productive process. In order to discover and illuminate these problems, this paper provides two contributions. Firstly, it constructs a network DEA model considering undesirable output, which makes efficiency value more practically significant. And then, we apply the improved network DEA model to evaluate efficiency and productivity for manufacturing industries in China, which consequently verifies the rationality and validity of the model from the perspective of empirical verification. Secondly, we adopt the Malmquist productivity index to decompose each stage of the productive process into efficiency change and technological change, to figure out the source of the total factor productivity growth.

\section{Methodology}

\subsection{Network DEA Model}

The ith decision-making unit is represented with $\mathrm{DMU}_{\mathrm{i}}$. The input of the first stage is $X_{i}=\left(x_{1 i}, \ldots, x_{m i}\right)$, and output $Z_{i}=\left(z_{1 i}^{g}, \ldots, z_{d_{1} i}^{g} ; z_{1 i}^{b}, \ldots, z_{d_{2} i}^{b}\right)$. Input of the second stage which is also the first stage's undesirable output employs the representation $Z_{i}^{b}=\left(z_{1 i}^{b}, \ldots, z_{d_{1} i}^{b}\right)$ and the output $Y_{i}=\left(y_{1 i}, \ldots, y_{s_{1} i}\right)$. Structure of two-stage system with undesirable output is illustrated in Figure1:

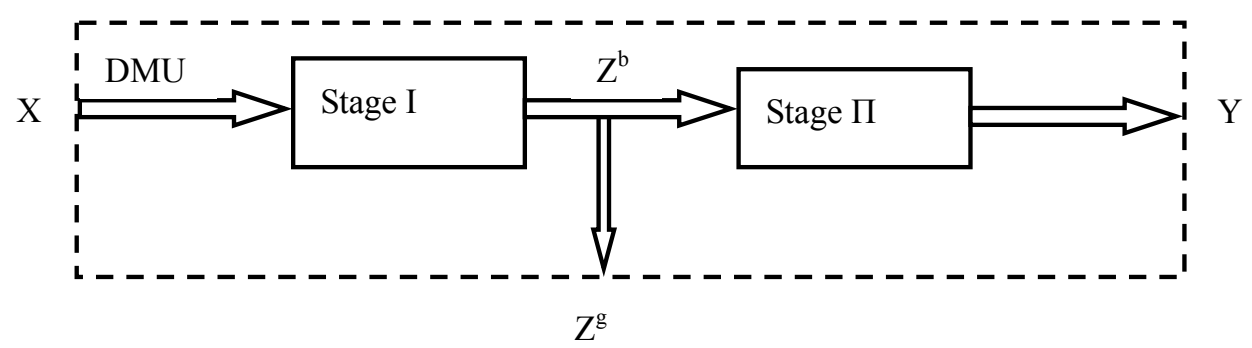

Figure 1. Structure of two-stage system that considers undesirable output

Concerning undesirable output, this article imitates Liu and Sharp's method. On the premises of guaranteeing the system effectiveness of Pareto Efficiency, they regard undesirable output as an input element to minimize undesirable output. Without considering sub-processes, two stages can be seen as a whole. That is to say, $\mathrm{X}$ acts as the input of the system, $\mathrm{Z}^{\mathrm{b}}$ and $\mathrm{Y}$ is the outputs of the system. We assume that $\mathrm{DMN}_{\mathrm{o}}$ is a unit awaiting 
assessment, under the constant returns to scale (CRS) assumption. The correspondent DEA efficiency model is:

$$
\theta_{b o x}^{*}=\max \frac{u^{g} Y_{o}}{v X_{o}+w^{b} Z_{o}^{b}}, \text { s.t., }\left(\frac{u^{g} Y}{v X+w^{b} Z^{b}} \leq 1, v \geq 0, w^{b} \geq 0, u^{g} \geq 0\right)
$$

For the fractional programming, we transform form (1) into linear programming model (2) by C-C transformation, thus the DEA efficiency of $\mathrm{DMU}_{\mathrm{o}}$ can be calculated.

$$
\theta_{b o x}^{*}=\max u^{g} Y_{o}, \text { s.t., }\left(-v X-w^{b} Z^{b}+u^{g} Y \leq 0, v X_{o}+u^{g} Z_{o}^{b}=1\right.
$$

If the whole production process is decomposed into two tandem sub-stages, $\left\{Z^{g}, Z^{b}\right\}$ are the intermediate products of the first stage. $Z^{b}$ enters into the second stage as an input. The final output is Y. If we consider the efficiency of every stage separately, the efficiency DEA models of each stage can be measured by model (3) and model (4).

The DEA efficiency model of the first stage is:

$$
\theta_{\text {sin } g l e-1}^{*}=\max \frac{w_{1}^{g} Z_{o}^{g}}{v X_{o}+w^{b} Z_{o}^{b}}, \text { s.t., }\left(\frac{w_{1}^{g} Z^{g}}{v X+w^{b} Z^{b}} \leq 1, v \geq 0, w_{1}^{g} \geq 0, w^{b} \geq 0\right)
$$

The DEA efficiency model of the second stage is:

$$
\theta_{\text {Sin } g l e-\pi}^{*}=\max \frac{u^{g} Y_{O}}{w_{\pi}^{b} z_{o}^{b}}, \text { s.t., }\left(\frac{u^{g} Y}{w_{\pi}^{b} z^{b}} \leq 1, u^{g} \geq 0, w_{\pi}^{b} \geq 0\right)
$$

We assume that the total productive process is constant returns to scale (CRS). $\theta_{1}$ and $\theta_{\pi}$ represent efficiency value in two stages respectively. $\varepsilon_{1}, \varepsilon_{\pi}$ give the first and second stage weighting factor accordingly. This paper interprets the weight as a proportion that resource consumption in the current stage occupying in the two stages' total resource consumption. The expression appears as shown below:

$$
\varepsilon_{1}=\frac{v X_{o}+w^{b} Z_{o}^{b}}{v X_{o}+w^{b} Z_{o}^{b}+w_{\pi}^{g} Z_{o}^{g}}, \quad \varepsilon_{\pi}=\frac{w_{\pi}^{b} z_{o}^{b}}{v X_{o}+w^{b} z_{o}^{b}+w_{\pi}^{g} z_{o}^{g}}
$$

Liang conceives that if subunit's input weight in the first stage is not equal to weight in the second, this approach is unable to reflect the cooperative relationship between the two stages. Thus this paper assumes $W_{\pi}^{g}=W_{1}^{g}=W^{g}$ and makes no request upon weight of $Z^{\mathrm{b}}$ Based on analysis above, the overall efficiency model, concerning undesirable output in the two stages, can be established as below:

$$
\theta_{\text {new-CRS }}^{*}=\max \frac{w^{g} Z_{o}^{g}+u^{g} Y_{o}}{v X_{o}+w^{b} Z_{o}^{b}+w^{g} Z_{o}^{g}} \text {, s.t., }\left(\frac{w^{g} Z^{g}}{v X+w^{b} Z^{b}} \leq 1, \frac{u^{g} Y}{w^{b} Z^{b}} \leq 1, u \geq 0, w^{g} \geq 0, w^{b} \geq 0, u^{g} \geq o\right)
$$

\subsection{Malmquist Index}

Malmquist productivity index (Malmquist, 1953) is designed to measure productivity change over time, which can be calculated from DEA efficiency scores (Fare et al., 1994; Berg et al., 1992; Førsund, 1993). It tells us how much the ratio of aggregate output to aggregate input (an index of average product) has changed between any two time periods (Mickael \& Magnus, 1999). Malmquist index employs a variety of input and output variables to analyze the efficiency, and does not need any price information. More importantly, it divided the reason for productivity change into technology change and efficiency change, which helps us to find the source of productivity change. Malmquist index adopts the ratio of distance function to calculate input-output efficiency, and the required information is just the data of input and output. There are three classic formulas to introduce the principle of Malmquist index. At the first stage, $X_{i}^{t}$ represents the input vector of the ith DMU at period $\mathrm{t}$ and $X_{i}^{t+1}$ at period $\mathrm{t}+1$. Accordingly, $Z_{i}^{t}, Z_{i}^{t+1}$ represent the output vector in the corresponding stage; the formula is listed as follows: 


$$
M_{i, i+1}\left(X_{i}^{t}, Z_{i}^{t}, X_{i}^{t+1}, Z_{i}^{t+1}\right)=\left[\frac{D_{i}^{t}\left(X_{j}^{t+1}, Z_{i}^{t+1}\right)}{D_{i}^{t}\left(X_{i}^{t}, Z_{i}^{t}\right)} * \frac{D_{i}^{t+1}\left(X_{j}^{t+1}, Z_{i}^{t+1}\right)}{D_{i}^{t+1}\left(X_{i}^{t}, Z_{i}^{t}\right)}\right]^{1 / 2}
$$

Transforming formula (8) can obtain formula (9):

$$
M_{i, i+1}\left(X_{i}^{t}, Z_{i}^{t}, X_{i}^{t+1}, Z_{i}^{t+1}\right)=\underbrace{\frac{D_{i}^{t+1}\left(X_{i}^{t}, Z_{i}^{t+1}\right)}{D_{i}^{t}\left(X_{i}^{t}, Z_{i}^{t}\right)}}_{E F_{i}^{t+1}}[\underbrace{\left.\frac{D_{i}^{t}\left(X_{i}^{t}, Z_{i}^{t}\right)}{D_{i}^{t+1}\left(X_{i}^{t}, Z_{i}^{t}\right)} * \frac{D_{i}^{t}\left(X_{i}^{t+1}, Z_{i}^{t+1}\right)}{D_{i}^{t+1}\left(X_{i}^{t+1}, Z_{i}^{t+1}\right)}\right]^{1 / 2}}_{T C_{i}^{t+1}}
$$

Formula (9) is used to indicate the separation of technical change and the efficiency change. EF is efficiency change between periods, and TC is the rate of technology change from stage $t$ to $t+1$.

In the second stage, the production process applies $Z$ inputs to produce $\mathrm{Y}$ outputs. So, $Z_{i}^{t}, Z_{i}^{t+1}$ represent the input vector at period $\mathrm{t}$ and $\mathrm{t}+1$ of the ith DMU respectively, $Y_{i}^{t}, Y_{i}^{t+1}$ represent the output vector at period $\mathrm{t}$ and $\mathrm{t}+1$.

$$
\begin{aligned}
& M_{i, i+1}\left(Z_{i}^{t}, Y_{i}^{t}, Z_{i}^{t+1}, Y_{i}^{t+1}\right)=\left[\frac{D_{i}^{t}\left(Z_{i}^{t+1}, Y_{i}^{t+1}\right)}{D_{i}^{t}\left(Z_{i}^{t}, Y_{i}^{t}\right)} * \frac{D_{i}^{t+1}\left(Z_{i}^{t+1}, Y_{i}^{t+1}\right)}{D_{i}^{t+1}\left(Z_{i}^{t}, Y_{i}^{t}\right)}\right]^{1 / 2} \\
& M_{i, i+1}\left(Z_{i}^{t}, Y_{i}^{t}, Z_{i}^{t+1}, Y_{i}^{t+1}\right)=\underbrace{\frac{D_{i}^{t+1}\left(Z_{i}^{t+1}, Y_{i}^{t+1}\right)}{D_{i}^{t}\left(Z_{i}^{t}, Y_{i}^{t}\right)}}_{E F_{i}^{t+1}}[\underbrace{\left[\frac{D_{i}^{t}\left(Z_{i}^{t}, Y_{i}^{t}\right)}{D_{i}^{t+1}\left(Z_{i}^{t}, Y_{i}^{t}\right)} * \frac{D_{i}^{t}\left(Z_{i}^{t+1}, Y_{i}^{t+1}\right)}{D_{i}^{t+1}\left(Z_{i}^{t+1}, Y_{i}^{t+1}\right)}\right]^{1 / 2}}_{T C_{i}^{t+1}}
\end{aligned}
$$

\section{Data}

\subsection{Sample}

The empirical study covers 28 Chinese manufacturing industries and selects the examples from1996 to 2011 . The reason of choosing those examples during this time span is based on the following three considerations: (1) Serious deficiencies of production data in the 1980s and intense uncertainty on DEA application effect. (2) From a policy perspective, China's economic development and reform in terms of power and pattern in 1990s is distinctive from 1980s' and the data of 1990s are superior to the preceding data. Thus, the production data since the 1990s has more research value. (3) Chinese industrial technology has been developing rapidly since 1990s, which has also promoted upgrading of industries. Questions about production efficiency evaluation gradually become a hot topic. Examples of this time span are able to help grasping the characteristics and changes of the production efficiency.

Table 1. Industries' two-digit code and ranking

\begin{tabular}{llllll}
\hline$I d$ & Ind & Ranking & Id & Ind & Ranking \\
\hline 14 & $\begin{array}{l}\text { Processing of Food from Agricultural } \\
\text { Products }\end{array}$ & 26 & 28 & Manufacture of Medicines & 18 \\
15 & Manufacture of Foods & 17 & 29 & Manufacture of Chemical Fibers & 24 \\
16 & Manufacture of Beverages & 14 & 30 & Manufacture of Rubber & 16 \\
17 & Manufacture of Tobacco & 5 & 31 & Manufacture of Plastics & 20 \\
18 & Manufacture of Textile & 31 & 32 & $\begin{array}{l}\text { Manufacture of Non-metallic Mineral } \\
\text { Products }\end{array}$ & 36 \\
19 & $\begin{array}{l}\text { Manufacture of Textile Wearing } \\
\text { Apparel, Footware, and Caps }\end{array}$ & 8 & 33 & $\begin{array}{l}\text { Smelting and Pressing of Ferrous } \\
\text { Metals }\end{array}$ & 38 \\
& $\begin{array}{l}\text { Manufacture of Leather, Fur, Feather } \\
\text { and Related Products Processing of }\end{array}$ & 6 & 34 & $\begin{array}{l}\text { Smelting and Pressing of Non-ferrous } \\
\text { Timber, Manufacture }\end{array}$ & 33 \\
\hline
\end{tabular}




\begin{tabular}{|c|c|c|c|c|c|}
\hline Id & Ind & Ranking & Id & Ind & Ranking \\
\hline 21 & $\begin{array}{l}\text { Processing of Timber, Manufacture of } \\
\text { Wood, Bamboo, Rattan, Palm, and } \\
\text { Straw Products }\end{array}$ & 10 & 35 & Manufacture of Metal Products & 27 \\
\hline 22 & Manufacture of Furniture & 1 & 36 & $\begin{array}{l}\text { Manufacture of General Purpose } \\
\text { Machinery }\end{array}$ & 25 \\
\hline 23 & $\begin{array}{l}\text { Manufacture of Paper and Paper } \\
\text { Products }\end{array}$ & 29 & 37 & $\begin{array}{l}\text { Manufacture of Special Purpose } \\
\text { Machinery }\end{array}$ & 21 \\
\hline 24 & $\begin{array}{l}\text { Printing, Reproduction of Recording } \\
\text { Media }\end{array}$ & 7 & 38 & Manufacture of Transport Equipment & 28 \\
\hline 25 & $\begin{array}{l}\text { Manufacture of Articles for Culture, } \\
\text { Education and Sport Activity }\end{array}$ & 4 & 39 & $\begin{array}{l}\text { Manufacture of Electrical Machinery } \\
\text { and Equipment }\end{array}$ & 19 \\
\hline 26 & $\begin{array}{l}\text { Processing of Petroleum, Coking, } \\
\text { Processing of Nuclear Fuel }\end{array}$ & 34 & 40 & $\begin{array}{l}\text { Manufacture of Communication } \\
\text { Equipment, Computers and Other } \\
\text { Electronic Equipment }\end{array}$ & 22 \\
\hline 27 & $\begin{array}{l}\text { Manufacture of Raw Chemical } \\
\text { Materials and Chemical Products }\end{array}$ & 37 & 41 & $\begin{array}{l}\text { Manufacture of Measuring } \\
\text { Instruments and Machinery for } \\
\text { Cultural Activity and Office Work }\end{array}$ & 3 \\
\hline
\end{tabular}

Note: Id stands for two-digit code. Ind represents industry. Ranking is obtained by sorting energy consumption from low to high of industry-level in 2004.

\subsection{Input and Output Variables}

Input and output variables are important to the accuracy of DEA model application. The production stage in this empirical research consists of four input indicators, three output indicators. The treatment stage of industrial pollution contains three input indicators and two output indicators, in line with demands of the DEA method which can be applied to evaluate unit number and the input-output index number. All these indicators are listed in Table 2.

The first stage is the production stage, energy consumption process. This stage produces major products which is also called desirable output. The productive process will produce some pollution, known as the undesirable output. At this stage, input indicators are measured from capital stock, labor force, energy and intermediate input. They are listed as follows:

1) Capital stock

This article calculates the capital stock for every industry by perpetual inventory method approximately, because the capital stock at every industry level cannot be obtained directly from the official statistics data.

2) Labor force

This study takes the average employment in each industry from 1996 to 2011 as the labor force indicator.

3) Energy

Energy consumption of industry is published in the energy yearbook of China in a form of physical quantity. The data should be transformed into standard quantity according to the calorific value.

4) Intermediate input

Industrial intermediate input refers to purchased goods and paid services consumed during the industrial production of enterprises. It can be calculated by the production approach as follows: industrial intermediate input $=$ Gross industrial output-Value-added of industry + value-added tax.

Output can be divided into desirable output and undesirable output. Output index selected in this article is listed as:

5) TO

Gross industrial output value is the total volume of final industrial products produced and industrial services provided during a given period in monetary terms. It reflects the total achievements and overall scale of industrial production during a given period. Gross industrial output value can be directly acquired from the statistical yearbook of China. We use Price Indices for Investment in Fixed Assets, so as to remove the factor of price change in the aggregates of investment at current prices. Regarding 1990 as the base year, DEA efficiency 
can be evaluated fairly.

6) Two kinds of industrial wastes

There are amounts of pollutants created in the economic production process. In terms of major emission of pollutants in the industrial production, this article sets $\mathrm{SO}_{2}(\mathrm{~S})$ and $\mathrm{COD}(\mathrm{C})$ as Pollutants output indicators. $\mathrm{SO}_{2}(\mathrm{~S})$ refers to volume of sulphur dioxide emission from fuel burning and production process for a given period of time. Its calculation formula is: Emission= $\mathrm{SO}_{2}$ Emission from Fuel Burning $+\mathrm{SO}_{2}$ Emission from Production Process. Chemical Oxygen Demand (COD) refers to index of water pollution measuring the mass concentration of oxygen consumed during chemical breakdown of organic and inorganic objects. Datum can be directly obtained from China statistical yearbooks from 1996 to 2011, National Bureau of Statistics.

The second stage is the treatment stage of industrial pollution (or say disposal of industrial pollution). It requires some necessary resources to clean pollutants of the first stage and transform into useful products. This paper considers new input indictors as:

7) Investments in industrial pollution control

Investments in industrial pollution control include solutions to water pollution and odor pollution. We use fixed price index for data processing so as to eliminate the factors of price change. Regarding 1990 as the base year, DEA efficiency can be evaluated fairly. Datum can be directly obtained from China statistical yearbooks from 1996 to 2011, National Bureau of Statistics.

8) Pollution-treatment facilities

Pollution-treatment facilities include facilities of disposals of wastewater and gas. Datum can be directly obtained from China statistical yearbooks from 1996 to 2011, National Bureau of Statistics.

9) Operation expenditure

Operation costs could be referred to expenditure of environmental governance. We use fixed price index for data processing so as to eliminate the factors of price change. Regarding 1990 as the base year, DEA efficiency can be evaluated fairly.

Two output indicators in the second stage are Ratio of industrial Waste Water Meeting Discharge Standards and Ratio of Industrial $\mathrm{SO}_{2}$ Emission Meeting Discharge Standards. Ratio of Industrial Waste Water Meeting Discharge Standards refers to percentage of industrial waste water meeting discharge standards over total industrial waste water discharge. It is calculated as: Ratio of Industrial Waste Water Meeting Discharge Standards $=$ Industrial Waste Water Meeting Discharge Standards/Total Industrial Waste Water Discharge $\times 100 \%$. The calculation method of Ratio of Industrial $\mathrm{SO}_{2}$ Emission Meeting Discharge Standards is the same as the previous one.

Table 2. Efficiency evaluation index system of total process

\begin{tabular}{|c|c|c|}
\hline Stage & & Index \\
\hline \multirow{7}{*}{ The production stage } & & Capital stock \\
\hline & & Labor force \\
\hline & Input & Energy \\
\hline & & Intermediate input \\
\hline & & TO \\
\hline & Output & $\mathrm{SO}_{2}$ \\
\hline & & COD \\
\hline \multirow{5}{*}{$\begin{array}{l}\text { Treatment } \\
\text { pollution }\end{array}$} & & Investments on industrial pollution control \\
\hline & Input & Facilities for Treatment \\
\hline & & Operation Expenditure \\
\hline & Output & $\begin{array}{l}\text { Ratio of industrial } \mathrm{SO}_{2} \text { Emission Meeting Discharge } \\
\text { Standards }\end{array}$ \\
\hline & & Ratio of Industrial Waste Water Meeting Discharge Standards \\
\hline
\end{tabular}




\section{Result}

\subsection{Efficiencies and TFP Obtained through Different DEA Models}

Efficiencies obtained by DEA model (1) and (7) are listed as:

Table 3. Efficiency and TFP obtained by different DEA models

\begin{tabular}{|c|c|c|c|c|}
\hline DUM & $\theta_{b o x}^{*}$ & $\theta_{\text {new-CRS }}^{*}$ & $\theta_{\text {new-CRS-1}}^{*}$ & $\theta_{\text {new }-C R S-\pi}^{*}$ \\
\hline$\# 14$ & 0.565 & 0.471 & 0.655 & 0.358 \\
\hline \#15 & 0.546 & 0.517 & 0.562 & 0.501 \\
\hline \#16 & 0.575 & 0.556 & 0.615 & 0.541 \\
\hline \#17 & 1.000 & 1.000 & 1.000 & 1.000 \\
\hline \#18 & 0.581 & 0.244 & 0.622 & 0.129 \\
\hline \#19 & 0.806 & 0.715 & 0.814 & 0.637 \\
\hline$\# 20$ & 0.623 & 0.688 & 0.689 & 0.688 \\
\hline \#21 & 0.627 & 0.600 & 0.639 & 0.566 \\
\hline \#22 & 0.809 & 1.000 & 1.000 & 1.000 \\
\hline$\# 23$ & 0.530 & 0.403 & 0.567 & 0.304 \\
\hline$\# 24$ & 0.921 & 0.899 & 0.913 & 0.884 \\
\hline$\# 25$ & 0.951 & 1.000 & 1.000 & 1.000 \\
\hline \#26 & 0.487 & 0.456 & 0.473 & 0.448 \\
\hline \#27 & 0.532 & 0.221 & 0.677 & 0.110 \\
\hline \#28 & 0.638 & 0.586 & 0.626 & 0.548 \\
\hline \#29 & 0.693 & 1.000 & 1.000 & 1.000 \\
\hline \#30 & 0.627 & 0.685 & 0.613 & 0.843 \\
\hline \#31 & 0.746 & 0.730 & 0.831 & 0.642 \\
\hline \#32 & 0.599 & 0.177 & 0.581 & 0.087 \\
\hline \#33 & 0.537 & 0.290 & 0.607 & 0.164 \\
\hline \#34 & 0.583 & 0.471 & 0.640 & 0.366 \\
\hline \#35 & 0.653 & 0.425 & 0.708 & 0.272 \\
\hline \#36 & 0.729 & 0.381 & 0.748 & 0.240 \\
\hline \#37 & 0.704 & 0.478 & 0.735 & 0.322 \\
\hline \#38 & 0.681 & 0.384 & 0.704 & 0.232 \\
\hline \#39 & 0.898 & 0.716 & 0.892 & 0.622 \\
\hline \#40 & 1.000 & 1.000 & 1.000 & 1.000 \\
\hline \#41 & 0.880 & 0.985 & 0.979 & 0.997 \\
\hline
\end{tabular}

Note: $\theta_{b o x}^{*}$ and $\theta_{\text {new-CRS }}^{*}$ represent the weighted average of DMUi's annual efficiency obtained from model (1) and model (6) respectively.

In order to compare the differences between the network DEA and the traditional one, here we also calculate the efficiency value of each DMU from the traditional model. By comparison, it shows that network DEA value of decision making units except that of $\# 20, \# 22, \# 25, \# 29$ and $\# 30$, is less than the traditional DEA value. The average efficiency value of network DEA is 0.601 , while that of the traditional one is 0.697 , which indicates that the network DEA can explore more inefficiency issues of the nodes and not simply evaluate the value as a whole. 
As for efficiency values at different stages, we have to figure out the source of DMU inefficiency. This is the network DEA's advantage lies in. For example, manufacture of metal products whose overall efficiency is 0.425 and for first stage and second stage are 0.708 and 0.272 respectively. It can be inferred that efficiency at first stage is comparatively higher, thus low efficiency at second stage is responsible for the overall low efficiency. The upgrade countermeasure should focus on progress in treatment stage of industrial pollution.

\subsection{Results for Three Industries Respectively}

28 manufacturing industries are divided into three types, shown in Table 4.

Table 4. 28 Industries are divided into 3 levels of energy-consumption industries

\begin{tabular}{ll}
\hline Group & Industries \\
\hline Low energy consumption industry & $(14),(15),(16),(17,(20),(22),(28),(35),(36),(37),(38),(39),(40),(41)$ \\
Medium energy consumption industry & $(18),(19),(24),(25),(26),(29),(30)$ \\
High energy consumption industry & $(21),(23),(27),(31),(32),(33),(34)$ \\
\hline
\end{tabular}

Note: Chinese industries are represented with two-digit code.

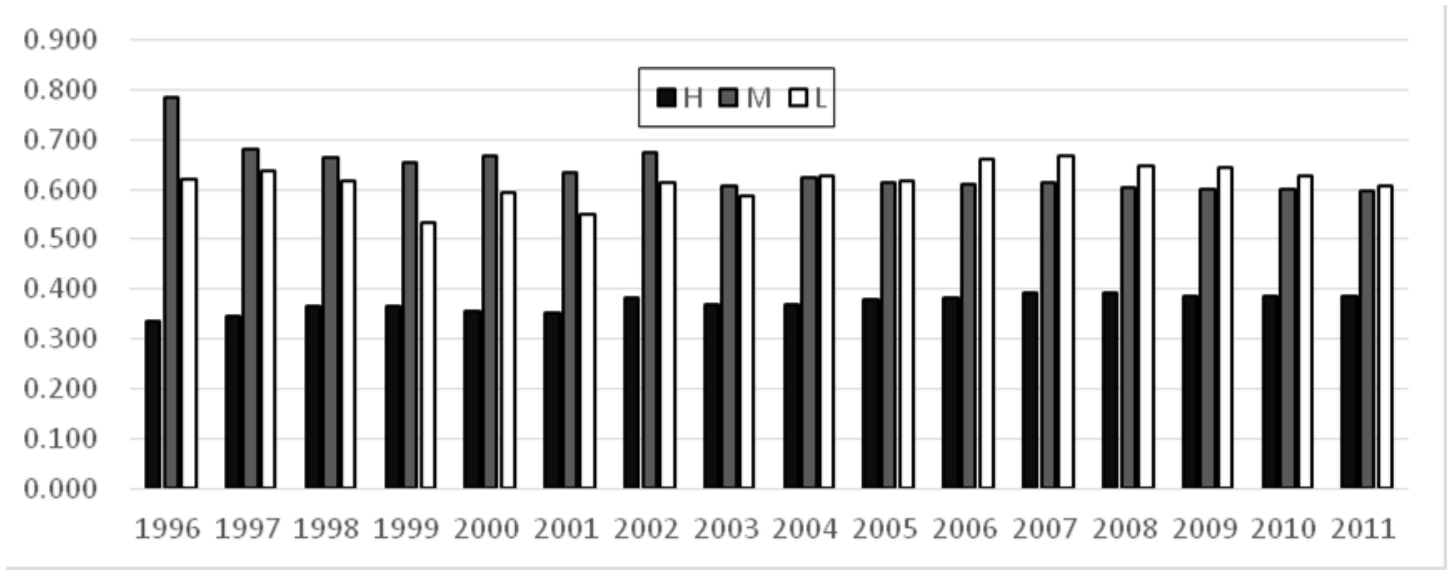

Figure 2. Efficiency for three industries

Comparing the efficiencies of the three industries, we find that the efficiency of the high energy consumption industry is the lowest while the two other are higher (Figure2). The efficiency score for high energy consumption industries, which bears the smallest changing amplitude, is at an average of 0.372 . The average score for Medium energy consumption industry efficiency (namely 0.639 ) is the highest. The efficiency demonstrates a downward trend.

As to the Low energy consumption industry, average score for the efficiency is $\sim 0.616$. Efficiency of Low energy consumption industry is lower than that of Medium energy consumption industry before 2006. Since 2006, the former starts to boost and catches up with the latter. China enacted the 12th five-year plan and established energy conservation and emissions reduction goals in 2006. The government strengthens the intensity of environmental regulation and bolsters the low energy consumption industry with policy support. These account for (explain) the efficiency promotion of low energy consumption industry since 2006. 


\subsection{TFP of China's Industries}

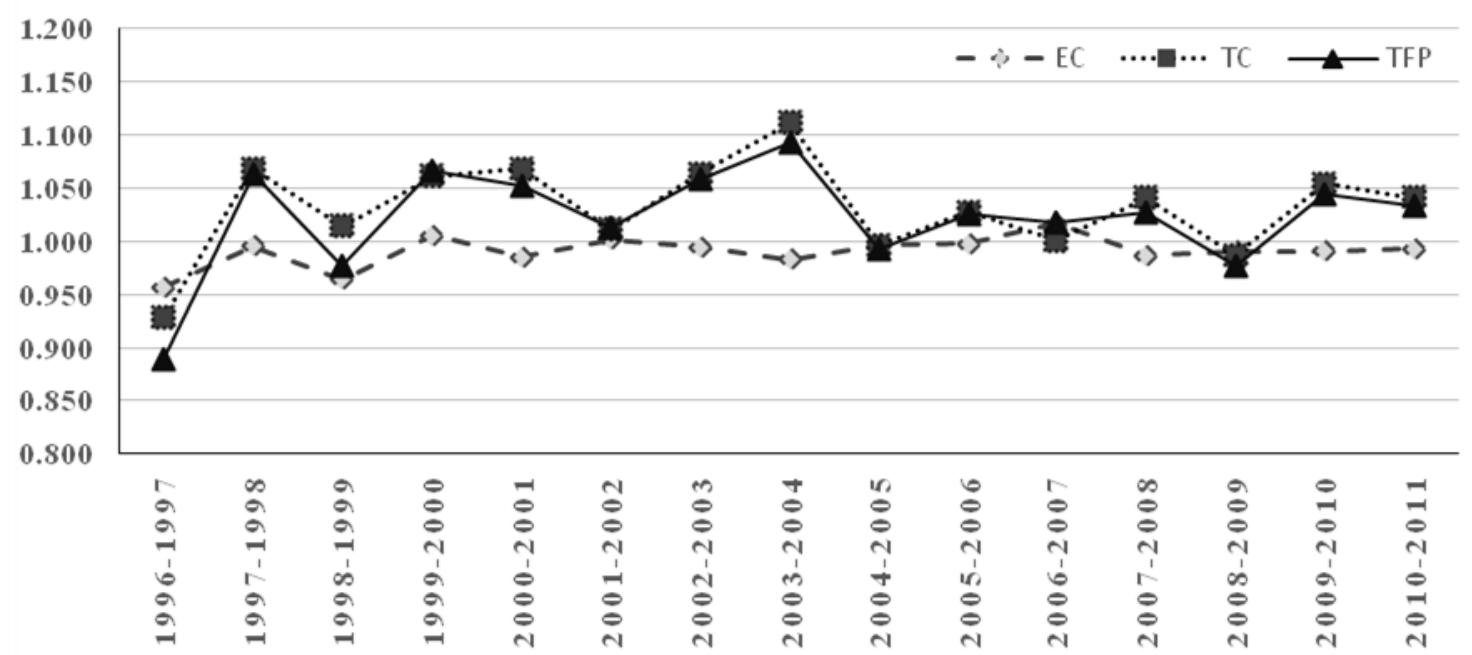

Figure 3. Changing trend of Chinese industries' TFP at production stage

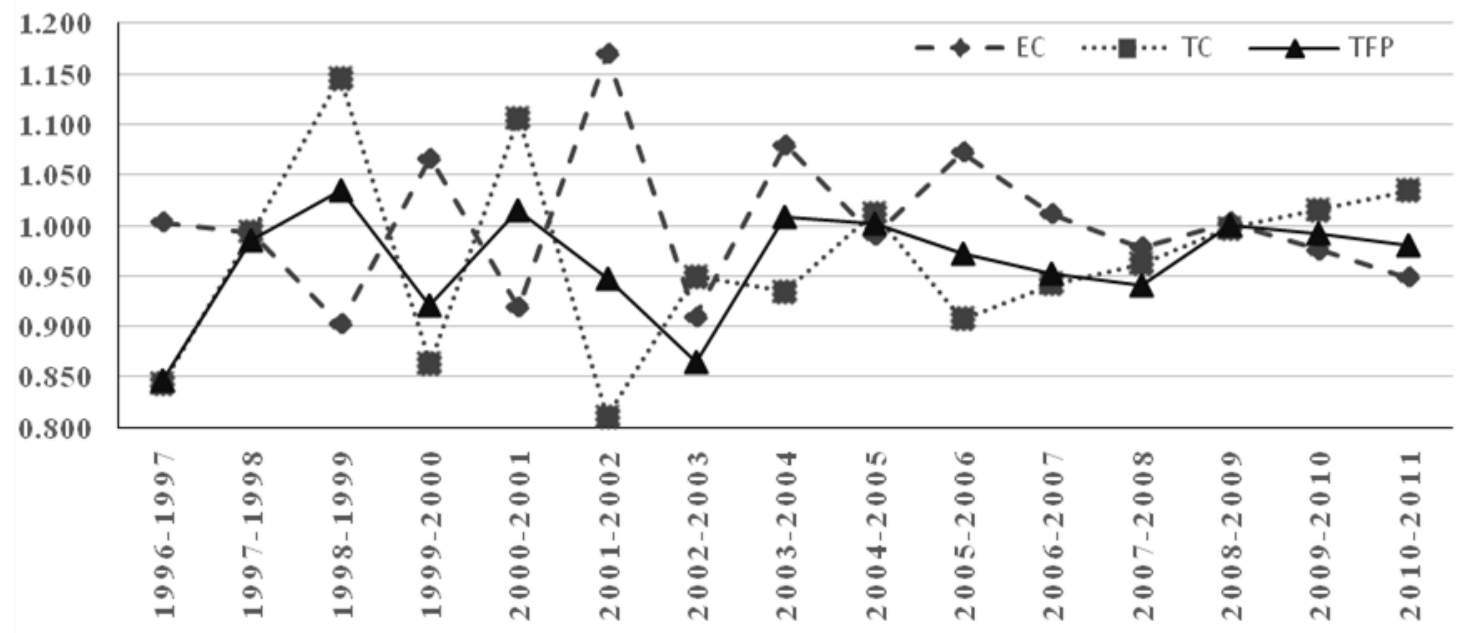

Figure 4. Changing trend of Chinese industries' TFP at treatment stage of industrial pollution

Figure3 and 4 manifest TFP variation trends at both production stage and treatment stage of industrial pollution. At production stage, from 1996 to 2011, TFP increases in volume by about 2.1 percent on average, EC decreases by $1.0 \%$, and TC increases by $3.1 \%$. In periods from 1999 to 2000 and 2006 to 2007, EC's value goes above 1, while it is below 1 in other periods and keeps small fluctuation. Meanwhile, the variation trend of TFP is basically consistent with that of TC. Aforementioned statistics and variation trend indicate that the overall increase of TFP stems mainly from TC improvement. At treatment stage of industrial pollution, from 1996 to 2011 , average decline of TFP is $0.38 \%$, average increase of EC is $0.5 \%$, and decline of TC $0.37 \%$. The three experience more intense fluctuation than that in production stage. Significantly different from production stage, as TC value changes from positive to negative, TFP decreases, all of these data implies the insufficient technology $R \& D$ at the treatment stage of industrial pollution 


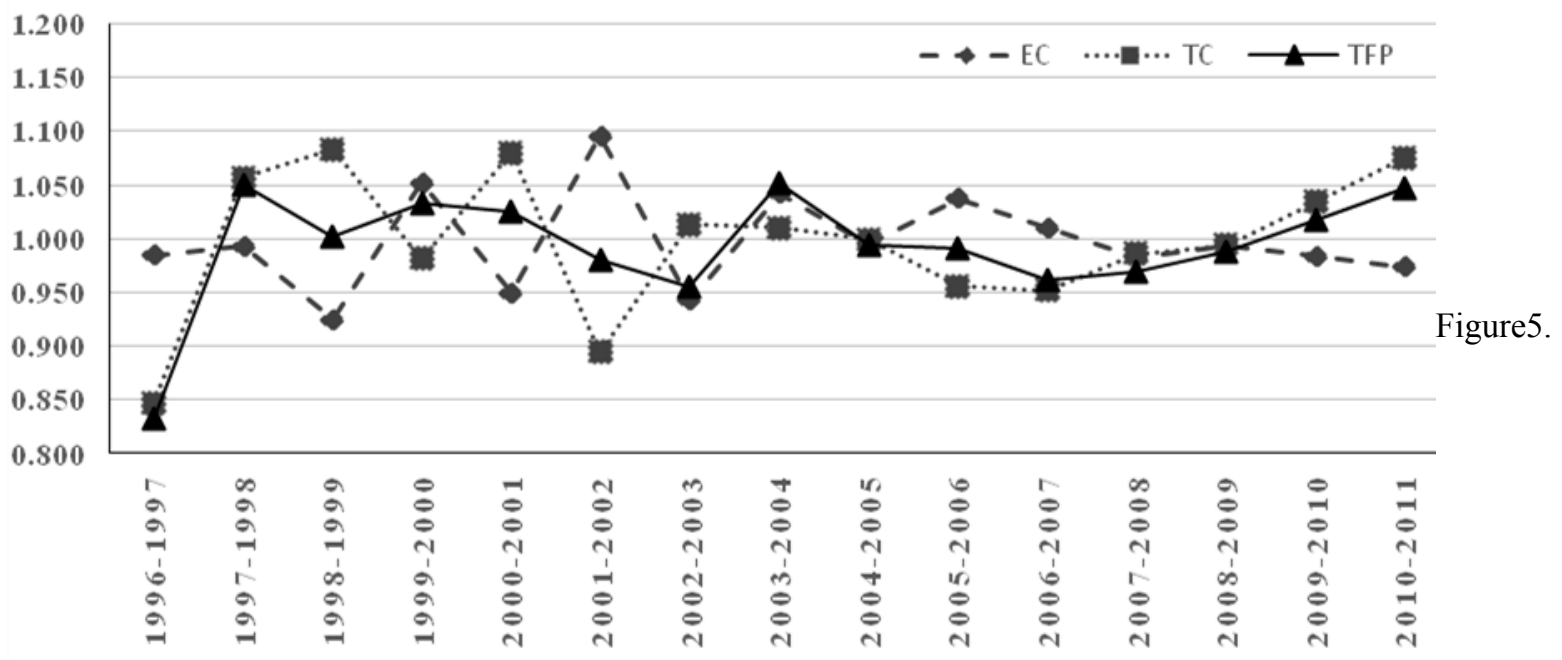

Figure 5. Changing trend of Chinese industries' TFP from a comprehensive perspective

From perspective of the average time series data on China's industry-level, the average growth rate of total factor productivity from 1996 to 2011 is $0.1744 \%$. Then probing into the decomposition of the mean total factor productivity results, technology change's average dynamic change is 1.0161 , with an efficiency improvement of $1.61 \%$. Average dynamic change of efficiency change (namely 1.0083 ) has increased by $0.827 \%$. According to the graphics changes, Productivity growth can be divided into three stages.

The first stage starts from 1996 to 2001. The main characteristic of this stage is that TFP presents a growth trend. Though TFP in 1996 decreased by $14.2 \%$, it is on the rise in the following years. A major driving force for TFP is the progress of the technology changes. The second stage is from 2001 to 2006 . Fluctuating drastically is the main characteristic in this period. TFP grows only in 2001 and 2004. Period from 2006 to 2011 can be called the third stage. From the overall situation, TFP of China's industries shows a rise first followed by a decline and then an overall growing trend. TFP at this stage keeps booming and reaches its ceiling value of 1.054 in 2011. The improvement of technical change accelerates the TFP growth. TC and TFP basically show a variation trend towards the same direction, while EC and TFP to opposite sides.

Upgrade of technology change makes contribution to the first stage growth. Especially, reform of the state-owned enterprises on a large scale and implementation of the export-oriented development strategy in mid and late 1990s; have led to a second climax of factors' efficiency improvement. And the structural reform on China's industry-level reached its second peak around 2001. Since 2001, extreme lag in development of factor market and malpractice in reform of industrial policy have been exposed, which creates sharp decrease in structural reform effect that is represented by factor allocation efficiency. TFP has fallen to its lowest level in 2006. These compose a backdrop for the TFP fluctuation in the second stage. Then after 2006, Chinese industries set out from its new growth point with the guidance of technology promotion.

\section{Conclusion}

This study is set in China's industrial efficiency evaluation. A new network DEA model considering undesirable output has been presented, and then applied to evaluation the efficiency for Chinese manufacturing industries from 1996 to 2011. According to application of the model, we can assess input/output structure of industrial production better than any other related methods. In the final analysis, this article utilizes Malmquist index to analyze productivity growth so as to figure out the source of growth. Base on the result and analysis of the result, we could roll out the following conclusions:

There exists black-box hypothesis in the traditional DEA model whose specific conversion process is not accurately described and simulated. Neglect of the internal structure leads to overestimate of the DMU's efficiency. This paper adopts the network DEA model and assumes the input-output conversion process properly by revealing the "black box". The efficiency value obtained depicts the efficiency value and sorting efficiency of DMU more accurately. 
This article compares the efficiency value of the three industries through sorting them into types. Industry with lower energy consumption shares a higher efficiency and smaller fluctuation. The reason lies in that low energy consumption industry corresponds with the development trend of the times. Accordingly, more resources should be put into and policies should be made to support the development of China's low energy consumption industry in the forthcoming years.

China's industrial TFP improves on the whole. However, it is just an alternating growth instead of a continuous one. Technical advance has become the core motivation of industrial productivity growth. Meanwhile, promotion of technology boosts the growth of productivity.

Based on the findings above, we suggest that China's government should pay more attention to the development of energy-saving and environment friendly industries. China is a developing country whose overall environmental governance efficiency in the process of its industrialization is still at a low level, confronting with the issue of environmental quality deterioration over a certain period of time. Chinese government should polish the environmental regulations by prompting industries with large undesirable output and reducing potential to improve their efficiency. China's government needs continuous investments in industrial technology innovation with the aim of improving industrial productivity and the efficiency in the treatment stage of industrial pollution.

\section{References}

Bi, G. B., Liang, L., \& Yang, F. (2007). A two-stage serial production system DEA model. Chinese Journal of Management Science, 15, 92-96.

Färe, R. (1989). Multilateral productivity comparisons when some outputs are undesirable. Review of Economies and Statistics, 1, 90-98. http://dx.doi.org/10.2307/1928055

Färe, R. (2004). Environmental performance an index number approach. Resource, and Energy Economics, 26(3), 343-352. http://dx.doi.org/10.1016/j.reseneeco.2003.10.003

Kaoru, T., \& Miki, T. (2014). Dynamic DEA with network structure: A slacks-based measure approach. Omega, 42(1), 124-131. http://dx.doi.org/10.1016/j.omega.2013.04.002

Lee, J. D. (2002). Estimation of the shadow prices of pollutants with production environment inefficiency. Journal of Environmental Management, 64(4), 365-375. http://dx.doi.org/10.1006/jema.2001.0480

Lewis, H. F., \& Sexton, T. R. (2004). Network DEA: Efficiency analysis of organizations with complex internal structure. Computers \& Operations Research, 31, 1365-1410. http://dx.doi.org/10.1016/S0305-0548(03) 00095-9

Liang, J. (2012). Environmental pollution losses over 2 trillion, pollution control is losing money or making money? Economic Information Daily, A1.

Liang, L., \& Yang, F. (2006). DEA models for supply chain efficiency evaluation. Annals of Operations Research, 145(1), 35-49. http://dx.doi.org/10.1007/s10479-006-0026-7

Mickael, L., \& Magnus. (1999). Productivity and customer satisfaction in Swedish pharmacies: A DEA network model. European Journal of Operational Research, 115(3), 449-458. http://dx.doi.org/10.1016/S0377-2217 (98)00177-5

Ming-Miin, Y., \& Erwin, T. J. L. (2008). Efficiency and effectiveness in railway performance using multi-activity network DEA model. Omega, 36(6), 1005-1017. http://dx.doi.org/10.1016/j.omega.2007.06. 003

National Bureau of Statistics of China. (n. d.). Chinese Energy Statistics Yearbook. Beijing: China Statistics Press.

National Bureau of Statistics of China. (n. d.). Chinese Statistics Yearbook. Beijing: China Statistics Press.

Shephard, R. W., \& Färe, R. (1975). A dynamic theory of production correspondences. Operations Research Centers, Berkley: University of California.

Wang, C. H., Gopal, R., \& Zionts S. (1997). Use of data envelopment analysis in assessing information technology impact on firm performance. Annals of Operations Research, 73, 191-213. http://dx.doi.org/10. 1023/A:1018977111455

Wu, J., \& Yan, H. (2012). A DEA model for efficiency evaluation with undesirable output: An application of paper mills along Huai River. International Journal of Sustainable Society. http://dx.doi.org/10.1504/ IJSSOC.2012.044673 
Yang et al. (2011). Modeling undesirable outputs in eco-efficiency evaluation to paper mills along the Huai River based on Shannon DEA. International Journal of Sustainable Society, 10(1), 36-47.

Yang, F., \& Ang, S. (2011). Conditional eco-efficiency measure from the perspective of pollution emission firms. International Journal of Sustainable Society, 3(3), 276-291. http://dx.doi.org/10.1504/IJSSOC.2011.041268

\section{Copyrights}

Copyright for this article is retained by the author(s), with first publication rights granted to the journal.

This is an open-access article distributed under the terms and conditions of the Creative Commons Attribution license (http://creativecommons.org/licenses/by/3.0/). 